\title{
Thermochromatographic behavior of iodine in 316L stainless steel columns when evaporated from lead-bismuth eutectic
}

\author{
Erik Karlsson $^{1,2} \cdot$ Jörg Neuhausen ${ }^{1}$ (1) $\cdot$ Robert Eichler $^{1,2} \cdot$ Ivan I. Danilov $^{1,2} \cdot$ Alexander Vögele $^{1} \cdot$ Andreas Türler $^{2}$
}

Received: 29 January 2021 / Accepted: 17 March 2021 / Published online: 21 April 2021

(c) The Author(s) 2021

\begin{abstract}
Iodine evaporated from lead-bismuth eutectic (LBE) has been examined with respect to its adsorption behavior on stainless steel in various gases to establish a base for safety evaluations on LBE based nuclear reactors. In inert conditions the iodine forms a single species with an adsorption enthalpy between -97 and $-106 \mathrm{~kJ} / \mathrm{mol}$. The adsorbed species is tentatively identified as bismuth monoiodide, BiI. Addition of moisture to the inert gas has no substantial influence on the adsorption behaviour. For the reducing hydrogen carrier gas depositions with adsorption enthalpies ranging from -87 to $-134 \mathrm{~kJ} / \mathrm{mol}$ were observed in dry and water saturated conditions. The larger variation of adsorption enthalpies compared to analogous experiments in helium likely result from surface effects induced by the reactive gas. Formation of highly volatile species such as hydrogen iodide $\mathrm{HI}$ was not observed. In oxidizing conditions multiple iodine species with adsorption enthalpies ranging from -67 to $-83 \mathrm{~kJ} / \mathrm{mol}$ were observed, with the exception of one experiment where only a lower limit of $-\Delta H_{\text {ads }}<64 \mathrm{~kJ} /$ mol could be determined due to high volatility. The species occurring in oxidizing atmosphere are most likely monatomic iodine, iodine oxides and hydroxides. While oxygen as a carrier gas changes the speciation of iodine to more volatile compounds, it also introduces a retentive effect on the evaporation of iodine from the LBE sample. These results provide important information that establish a better understanding of safety related aspects pertaining to iodine transport in an LBE reactor. The determined thermodynamic data can be used for safety assessments of LBE-based nuclear facilities in normal operation conditions as well as for accident scenarios.
\end{abstract}

Keywords Iodine $\cdot$ Lead-bismuth eutectic $\cdot$ Thermochromatography $\cdot$ Stainless steel $\cdot$ Adsorption

\section{Introduction}

In an effort to extend the capabilities of the current fleet of nuclear reactors to enhance efficient use of nuclear fuel and reduce the burden of high active waste, we must look beyond light-water reactors (LWRs). The design of an LWR has water working as both the coolant and the moderator. This choice introduces compromises in both of those areas, which limit the ideal performance of the reactor both from a fuel usage and from a safety standpoint.

Lead-bismuth eutectic (LBE, 55.5\%/44.5\% Bi/Pb) cooled reactors present an answer to these problems with

Jörg Neuhausen

joerg.neuhausen@psi.ch

1 Laboratory of Radiochemistry, Paul Scherrer Institut (PSI), Forschungsstrasse 111, 5232 Villigen, Switzerland

2 Department of Chemistry and Biochemistry, University of Bern, Freiestrasse 3, 3012 Bern, Switzerland good neutronic properties allowing abundant fast neutrons as well as excellent thermal properties with a melting point of $123{ }^{\circ} \mathrm{C}$ and a boiling point of $1670{ }^{\circ} \mathrm{C}$ reducing the risk of loss-of-coolant accidents by boiling [1]. More efficient fuel usage through transmutation is the main goal of the reactor concerned in this work, the MYRRHA (Multi-purpose hYbrid Research Reactor for High-tech Applications). The MYRRHA is an accelerator driven system (ADS), a nuclear reactor with a proton beam impacting a spallation target inside the core to produce excess neutrons to sustain criticality. This configuration enables it to perform nuclear transmutation while sustaining the fission reaction to increase the burn-up of the fuel beyond what would be possible in conventional LWRs [2].

To be able to utilize such systems in full scale, there are questions related to safe operation and accident mitigation, which must be answered first. For example, the chemistry of fission products released from the fuel and allowed to migrate inside of the reactor structure has been well studied 
for LWRs [3-5], but corresponding information is still lacking for the LBE-reactor field. One downside of the choice of an LBE coolant is a large production of polonium occurring due to the constant irradiation of ${ }^{209} \mathrm{Bi}$ that makes up the majority of the coolant. The majority of this polonium was expected to remain inside the $\mathrm{LBE}$ as $\mathrm{PbPo}$, however potential fractional volatilization was a concern. Experiments on evaporating polonium from LBE in an atmosphere with traces of moisture showed a substantial increase in volatility for a small fraction of the polonium [6]. This sparks questions about the behavior of fission products in LBE when exposed to certain conditions such as moisture or oxidizing/ reducing environments. While thermodynamic calculations and experiments on macroscopic amounts of elements can indicate a behavior for the bulk of a fission product, low mole fraction experiments using carrier-free samples give an indication on the behavior at trace levels, which would otherwise perhaps have been missed. An example of such a situation would be the calculated speciation of the iodine inventory in the LBE. Thermodynamic calculations using data from the binary $\mathrm{Pb}-\mathrm{I}$ and $\mathrm{Bi}-\mathrm{I}$ systems $[7,8]$ suggests formation of $\mathrm{PbI}_{2}$ and $\mathrm{BiI}_{3}$. However, the ternary $\mathrm{Pb}-\mathrm{Bi}-\mathrm{I}$ system has not been investigated yet, and it is questionable whether at the mole fractions of iodine which are postulated to be present in the LBE (at multiple pin break conditions) the formation of these iodine-rich phases would occur [9, 10]. The potential formation of volatile iodine species influenced by reactive carrier gases or moisture is also a concern that must be addressed.

Determining the adsorption behavior of iodine species formed in certain conditions is vital to give a clear image of its behavior and transport in the event of an accident. This gives indications of the expected levels of release and if these are not acceptable, retentive efforts can also be evaluated using the same methodology. Such efforts may include the introduction of materials to which the species have higher affinity. The postulated main structural material for the MYRRHA reactor is 316L stainless steel. This material was chosen mainly due to its corrosion resistance when in contact with heated LBE for extended periods of time [1]. The 316L alloy is austenitic and consists mainly of $\mathrm{Fe}, \mathrm{Cr}$, Ni and Mo with the L signifying a reduced carbon content.

The thermochromatographic method used in the present work allows to study the adsorption behavior of volatile species on a certain material at very low mole fractions under various chemical conditions [11]. The method is based on evaporating a volatile radioactive species into an inert or reactive carrier gas of defined composition. The species or its reaction products are then carried with the carrier gas through a hollow column or tube made out of the adsorbing material that is exposed to a negative temperature gradient. Different chemical species will deposit at characteristic temperatures in the gradient tube. The deposition patterns are then measured using the radioactive emissions of the deposited material. In the case that chemical equilibrium conditions for the adsorption process prevail thoughout the experiment, with defined stable chemical states of gas phase species and the surface, thermodynamic data can be extracted from the deposition pattern. In particular, values for the enthalpy of adsorption can be determined using a versatile mathematical model employing Monte-Carlo simulations described in reference [11].

Classically, when performing such adsorption chromatography experiments, the surface used is generally inert or at least unreactive with respect to influence from the carrier gas [11]. In the case of stainless steel, this is not the case as the present metals are not noble and capable of changing their chemical state. This leads to formation of oxide layers in oxidizing conditions and potentially a surface in the metallic state in reducing conditions. Such changes would affect the adsorption behavior and introduce variability in the iodine-steel interaction. Introduction of reactive gases such as hydrogen and oxygen would be initiated in an accident scenario by the compromising of the integrity of the reactor vessel or the steam generators, with water reacting with heated metals to produce hydrogen. This may lead to gradual surface changes in the steel, the extent of which will be determined by parameters such as the duration of the accident transient and the prevailing temperatures. Gradual changes in surface conditions when using stainless steel for chromatographic experiments have been observed for polonium in an oxygen atmosphere. Longer pre-treatment (exposure to oxygen and heat) of the column before the introduction of polonium into the system lead to a weaker sticking interaction, lowering the deposition temperature by up to $100{ }^{\circ} \mathrm{C}$ [12]. Similarly, in dry hydrogen carrier gas a pre-treatment of the column increased the deposition temperature by about $270{ }^{\circ} \mathrm{C}$ for a presumed metallic Po deposition. We expect this effect to play a role in the experiments with iodine on stainless steel performed in the present study as well, which is advantageous, because the task is to probe realistic conditions in various scenarios of operation of the reactor including potential accidents.

\section{Experimental}

\section{Sample preparation}

The lead bismuth eutectic samples containing non-carrieradded amounts of iodine used in this work were prepared by mixing the LBE with tellurium precursor and subsequent neutron irradiation according to a method described in [13]. The LBE (55.5/44.5\% Bi/Pb, SIDECH, 99.999\% purity) was reduced in oxygen content by heating it in an evacuated 
tantalum-lined fused silica ampoule at $1000{ }^{\circ} \mathrm{C}$. In a second step, the reduced LBE was then mixed in $2 \mathrm{~g}$ batches with 2 mass \% of tellurium metal granules (Sigma-Aldrich, 99.999\% purity, Batch MKBW7373V) in an evacuated fused silica ampoule at $850{ }^{\circ} \mathrm{C}$. To produce the desired ${ }^{131} \mathrm{I}$, the sample was irradiated at the SINQ pneumatic rabbit neutron irradiation facility at the NAA position with a thermal neutron flux of $10^{13} \mathrm{n} \mathrm{cm}^{-2} \mathrm{~s}^{-1}$ for $10,000 \mathrm{~s}$. This irradiation produces a homogeneous sample of LBE doped with carrier free iodine at a specific activity of approximately $300 \mathrm{~Bq} \mathrm{mg}^{-1}$. From this mother sample, smaller samplings were cut easily using a pair of pliers, as LBE is a very soft alloy.

\section{Experimental setup and procedure}

The sample of LBE (approx. 20-50 mg) was placed in an SS316L steel boat inside a tube, with a piece of quartz wool behind and in front of it to hold it in place as well as to capture eventual aerosols. The tube consists of 316L stainless steel (SS316L, Sandvik/Swagelok Lot: 35,828 ) with a $4 \mathrm{~mm}$ inside diameter and a length of $120 \mathrm{~cm}$ (experiments with water saturated gases) or $105 \mathrm{~cm}$ (experiments with dry gases) and was used as delivered, without any prior pretreatment. This tube was placed inside one of two gradient furnaces, one used for dry and another for water saturated carrier gases. The gradient furnaces had a temperature ranging from 700 or $1000{ }^{\circ} \mathrm{C}$ at the hottest position down to $25{ }^{\circ} \mathrm{C}$ along the carrier gas flow direction. Each experiment was initiated by evaporating the sample into the carrier gas. Carrier gases used were helium, hydrogen and oxygen, all Messer 5.0®. The flow of the carrier gases was adjusted using a mass flow controller (Brooks Instrument B.V., 5850S/E) to $25 \mathrm{ml} \mathrm{min}^{-1}$ (all water saturated gases), $25 \mathrm{ml} \mathrm{min}^{-1}\left(\mathrm{O}_{2}\right.$, dry $), 28 \mathrm{ml} \mathrm{min}^{-1}\left(\mathrm{H}_{2}\right.$, dry $), 45 \mathrm{ml} \mathrm{min}^{-1}$ (He, dry), verified using a mini-BUCK calibrator (A.P. Buck Inc.)
In dry conditions, the evaporation was initiated by switching on the starting furnace and in water saturated conditions the sample was pushed into the hot zone using a pin. The experimental time was two hours in water saturated conditions and three hours in dry conditions. The two furnace setups used in this work are depicted with their components in Fig. 1. In dry conditions the setup featured a gas loop with a SICAPENT ${ }^{\circledR}$ drying cartridge, a tantalum oxygen getter and a dew point meter (Michell Easidew EA2 - TX - 100). The $\mathrm{H}_{2} \mathrm{O}$ level in the system was monitored until it reached satisfactory conditions $(<125 \mathrm{ppm})$ at which point the experiment was started. For water saturated conditions, the carrier gas was led through a bubbler before entering the furnace. Because only one dew point meter was available for the parallel series of experiments in dry and moist conditions, the dew point was not measured explicitely for each individual experiment in the water saturated experiment series. Instead, a number of experimental runs with the same setup were performed after the actual experiment series, using non-radioactive samples and keeping all other parameters identical to the original experiments. In these experiments, all three different carrier gases were used, and additionally also the filling level of the water bubbler was varied. In these experiments, dew points between 6 and $8{ }^{\circ} \mathrm{C}$ were measured depending on the fill level of the bubbler, yielding moisture levels between 9300 and 10,700 volume-ppm.

When the experiment time expires, the gradient furnace is turned off stopping the movement of the iodine in the tube. To measure the activity distribution and thus the deposition of iodine present inside the tube, a lead collimator with a $1 \mathrm{~cm}$ hole was used to allow an HPGe $\gamma$-detector to measure the tube centimeter by centimeter on the $364.5 \mathrm{keV}$ line of ${ }^{131} \mathrm{I}$ [14]. The measured deposition pattern of iodine inside the tube is then fed as input data to a Monte Carlo simulation described in [11]. This simulates the transport of one radionuclide atom at a time through the tube. It takes into account experimental data

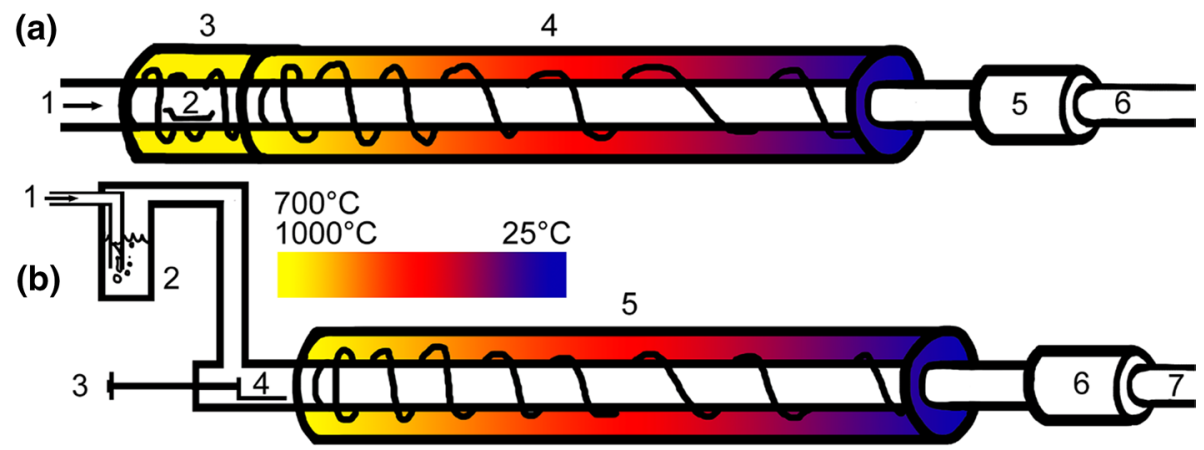

Fig. 1 Drawing of the two experimental setups used with arrows displaying the carrier gas flow direction. Furnace setup for dry conditions (a) featuring 1. Gas inlet, 2. Sample, 3. Starting furnace, 4. Gradient furnace, 5. Charcoal filter, 6. Gas outlet. Furnace setup for water saturated conditions (b) featuring 1. Gas inlet, 2. Water bubbler, 3. Sample pusher pin, 4. Sample, 5. Gradient furnace, 6. Charcoal filter, 7. Gas outlet 
such as for example time, molar mass of radionuclide species and carrier gas, gas flow velocity, the most prominent phonon frequency of the stationary phase (tube), the temperature gradient as well as a guess for the adsorption enthalpy $\Delta H_{a d s}$. The simulation process is iterative, where the guess for the enthalpy is altered until the simulation output matches the deposition pattern measured inside the tube.

(a)

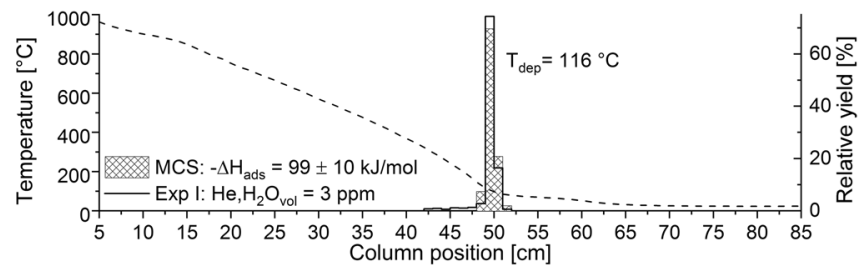

(c)

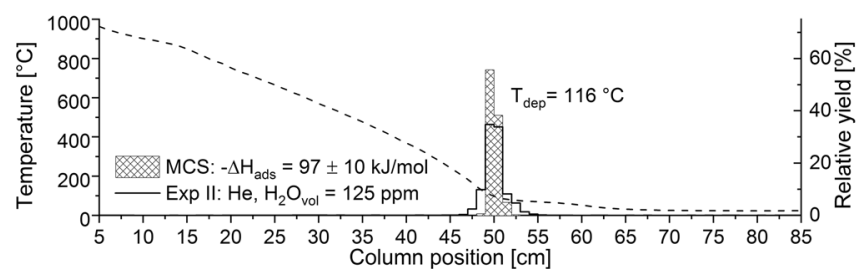

Fig. 2 Deposition patterns of experiments I-IV using helium as carrier gas (gas flow direction left to right; black dashed line: temperature gradient; solid black step line: measured deposition pattern; hatched histograms: output from the Monte Carlo simulation). On the

(a)

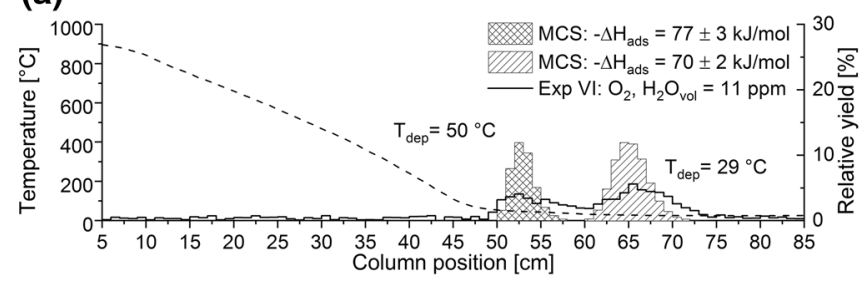

(b)

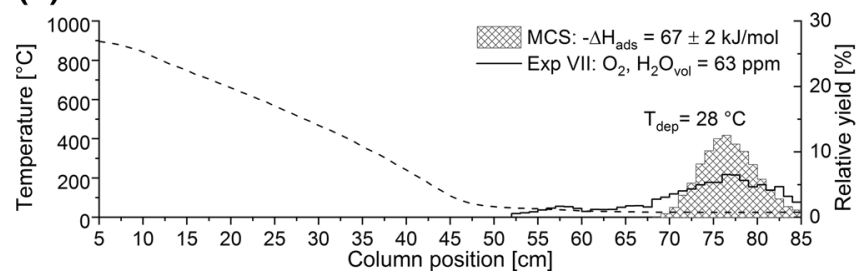

Fig. 3 Deposition patterns of experiments VI-IX using oxygen as carrier gas (gas flow direction left to right; black dashed line: temperature gradient; solid black step line: measured deposition pattern; hatched histograms: output from the Monte Carlo simulation). On the left side, experiments a and $\mathbf{c}$ with dry oxygen are depicted and on

\section{Results and discussion}

In this part, the results are presented divided into three sections according to the carrier gas used, with the resulting deposition patterns displayed in Figs. 2 to 5. The adsorption enthalpy determined using the Monte Carlo simulation described briefly above and in more detail in [11] as well as data regarding each experiment is compiled for all experiments in Table 1. The uncertainties have been estimated by varying the temperature at the deposition point by an amount

(b)

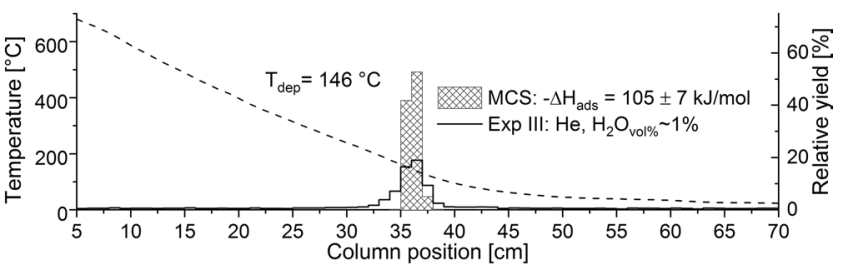

(d)

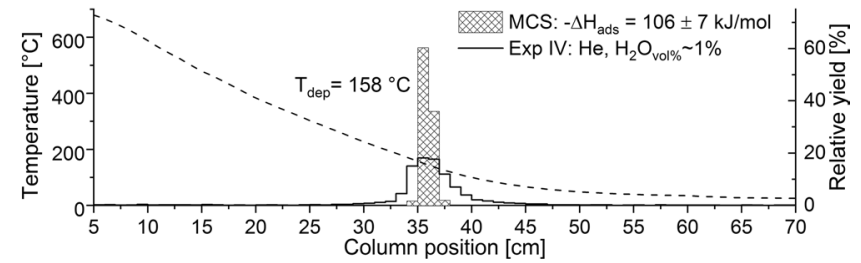

left side, experiments $\mathbf{a}$ and $\mathbf{c}$ with dry helium are depicted and on the right the water saturated ones $\mathbf{b}$ and $\mathbf{d}$. Deposition temperatures, carrier gas water content as well as Monte Carlo calculated adsorption enthalpies for each peak are also shown (b)

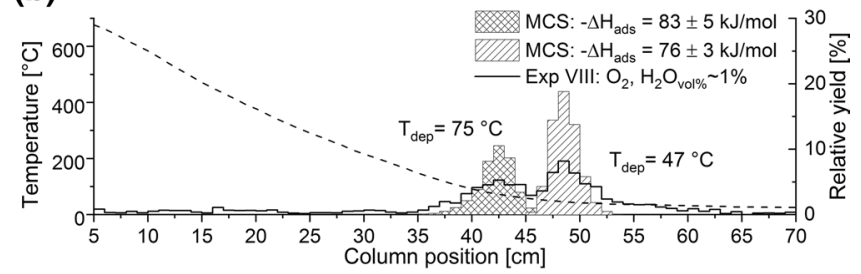

(d)

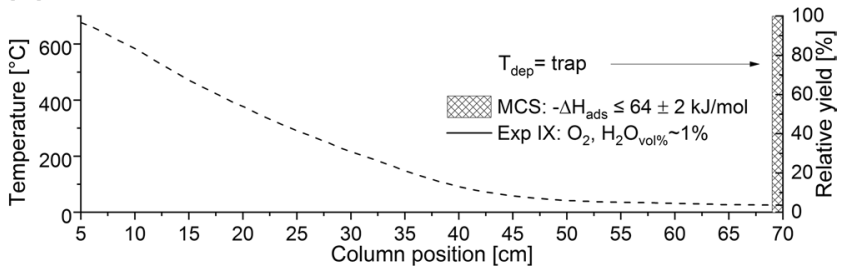

the right the water saturated ones $\mathbf{b}$ and $\mathbf{d}$. Deposition temperatures, carrier gas water content as well as Monte Carlo calculated adsorption enthalpies for each peak are also shown. In d) there was only a deposition in the charcoal trap hence the deposition temperature is effectively not shown 


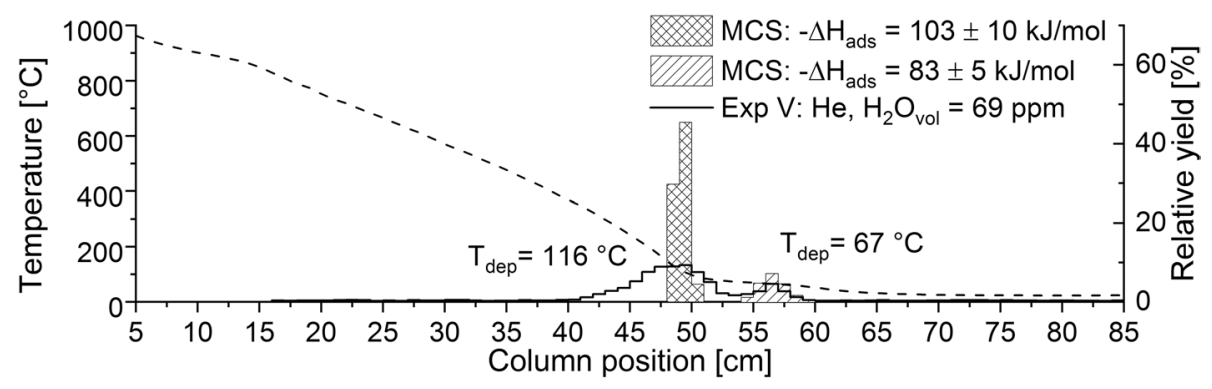

Fig. 4 Deposition pattern of experiment $\mathrm{V}$ using helium as carrier gas on a non-reduced sample of LBE (gas flow direction left to right; black dashed line: temperature gradient; solid black step line: measured deposition pattern; hatched histograms: output from the Monte
Carlo simulation). Deposition temperatures, carrier gas water content as well as Monte Carlo calculated adsorption enthalpies for each peak are also shown (a)

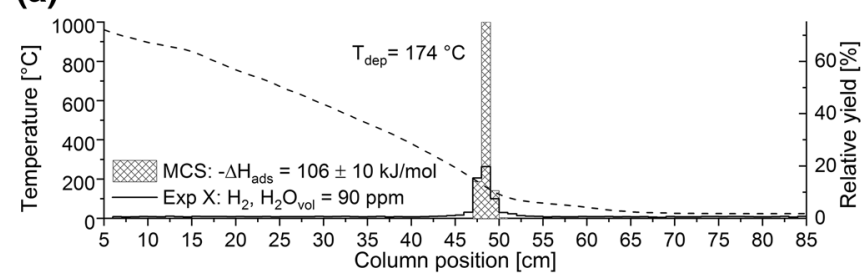

(c)

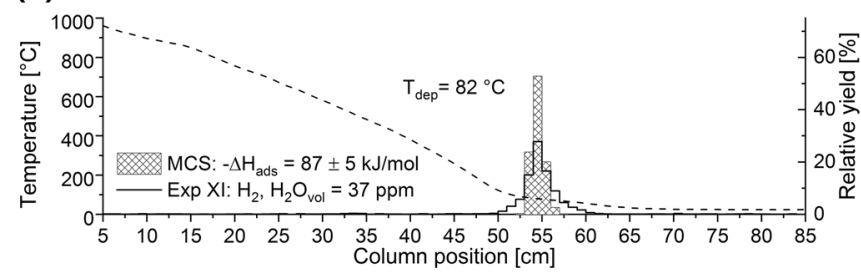

Fig. 5 Deposition patterns of experiments X-XIII using hydrogen as carrier gas (gas flow direction left to right; black dashed line: temperature gradient; solid black step line: measured deposition pattern; hatched histograms: output from the Monte Carlo simulation). On the (b)

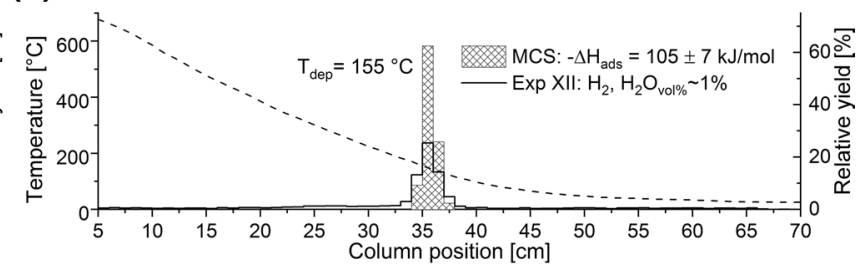

(d)

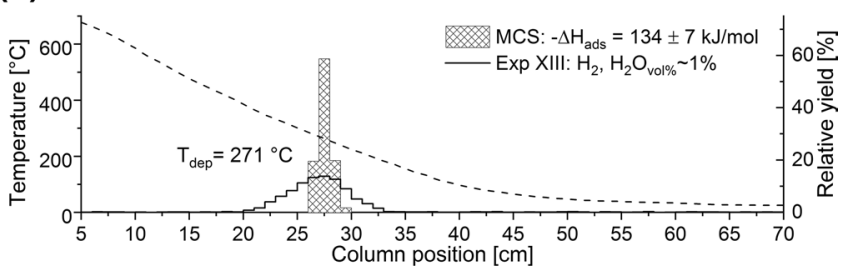

left side, experiments a and $\mathbf{c}$ with dry hydrogen are depicted, and on the right the water saturated ones $\mathbf{b}$ and $\mathbf{d}$. Deposition temperatures, carrier gas water content as well as Monte Carlo calculated adsorption enthalpies for each peak are also shown

normal operation [2]. A recent critical assessment of the few existing studies on iodine evaporation from LBE [9] indicates that at low concentrations the species evaporated from LBE is not lead diiodide or bismuth triiodide as would be suggested by literature on the binary $\mathrm{Pb}-\mathrm{I}[7]$ and $\mathrm{Bi}-\mathrm{I}$ systems [8]. At the mole fractions of iodine present in our system $\left(\sim 10^{-10}\right)$ formation of molecules with more than one iodine atom is highly unlikely. Thermodynamic calculations performed in a previous work support that the most prominent molecular iodine species over a dilute solution is bismuth monoiodide, BiI [15]. Depending on the distribution of various metals on the surface of the steel and the ratio of the number of atoms in the metallic and oxidic states, the adsorption behavior of this species will vary. For steel with no surface treatment exposed to an inert gas, the majority of the surface is made up of chromium/iron oxides and hydroxides in a corrosion resistant layer [16]. The observed behavior observed in dry inert gas is to be expected during 
Table 1 Experimental parameters for all experiments

\begin{tabular}{|c|c|c|c|c|c|c|}
\hline Exp & Gas & $\begin{array}{l}\mathrm{H}_{2} \mathrm{O} \text { concentration in gas } \\
\text { volume }(\mathrm{ppm})^{\mathrm{b}}\end{array}$ & Dew point $\left({ }^{\circ} \mathrm{C}\right)$ & $-\Delta H_{a d s}\left(\mathrm{~kJ} \mathrm{~mol}^{-1}\right)$ & $T_{d e p}\left({ }^{\circ} \mathrm{C}\right)$ & Tentative chemical speciation \\
\hline I & $\mathrm{He}$ & 3 & -69 & $99 \pm 10$ & 116 & BiI \\
\hline II & $\mathrm{He}$ & 125 & -40 & $97 \pm 10$ & 116 & BiI \\
\hline III & $\mathrm{He}$ & $\sim 10,000 \pm 700$ & $\sim 7 \pm 1$ & $105 \pm 7$ & 146 & BiI \\
\hline IV & $\mathrm{He}$ & $\sim 10,000 \pm 700$ & $\sim 7 \pm 1$ & $106 \pm 7$ & 158 & BiI \\
\hline \multirow[t]{2}{*}{$\mathrm{V}^{\mathrm{a}}$} & \multirow[t]{2}{*}{$\mathrm{He}$} & \multirow[t]{2}{*}{69} & \multirow[t]{2}{*}{-45} & $103 \pm 10$ & 116 & BiI \\
\hline & & & & $83 \pm 5$ & 67 & I \\
\hline \multirow[t]{2}{*}{ VI } & \multirow[t]{2}{*}{$\mathrm{O}_{2}$} & \multirow[t]{2}{*}{11} & \multirow[t]{2}{*}{-60} & $77 \pm 3$ & 50 & I \\
\hline & & & & $70 \pm 2$ & 29 & Iodine oxides/hydroxides \\
\hline VII & $\mathrm{O}_{2}$ & 63 & -46 & $67 \pm 2$ & 28 & Iodine oxides/hydroxides \\
\hline \multirow[t]{2}{*}{ VIII } & \multirow[t]{2}{*}{$\mathrm{O}_{2}$} & \multirow[t]{2}{*}{$\sim 10,000 \pm 700$} & \multirow[t]{2}{*}{$\sim 7 \pm 1$} & $83 \pm 5$ & 75 & I \\
\hline & & & & $76 \pm 3$ & 47 & Iodine oxides/hydroxides \\
\hline IX & $\mathrm{O}_{2}$ & $\sim 10,000 \pm 700$ & $\sim 7 \pm 1$ & $\leq 64 \pm 2$ & $\operatorname{trap}^{\mathrm{c}}$ & Iodine oxides/hydroxides \\
\hline $\mathrm{X}$ & $\mathrm{H}_{2}$ & 90 & -43 & $106 \pm 10$ & 174 & BiI \\
\hline $\mathrm{XI}$ & $\mathrm{H}_{2}$ & 37 & -50 & $87 \pm 5$ & 82 & BiI \\
\hline XII & $\mathrm{H}_{2}$ & $\sim 10,000 \pm 700$ & $\sim 7 \pm 1$ & $105 \pm 7$ & 155 & BiI \\
\hline XIII & $\mathrm{H}_{2}$ & $\sim 10,000 \pm 700$ & $\sim 7 \pm 1$ & $134 \pm 7$ & 271 & BiI \\
\hline
\end{tabular}

For each experiment the carrier gas, the water content in ppm and the corresponding dew point in ${ }^{\circ} \mathrm{C}$ are shown along with the adsorption enthalpies $\left(-\Delta H_{a d s}\right)$ determined using Monte Carlo simulation and the deposition temperature for the observed chromatographic peaks $\left(T_{d e p}\right)$. In the last column a tentative chemical speciation is given

${ }^{a}$ Experiment using LBE sample produced without reduction of oxygen content using tantalum foil

${ }^{\mathrm{b}}$ Calculated from dew point using humidity calculator offered by Michell Instruments at http://www.michell.com/uk/calculator/

${ }^{\mathrm{c}}$ see text for explanation

adsorption enthalpies on $316 \mathrm{~L}$ steel are very similar to what was observed on a fused silica surface which is oxidic in character $\left(-\Delta H_{a d s} \approx 100\right.$ to $\left.110 \mathrm{~kJ} \mathrm{~mol}^{-1}\right)$ [15]. This suggests that the bonding behavior of bismuth monoiodide on both oxidic surfaces is quite similar. This similarity in behavior also indicates that no reaction occurs between the metallic adsorption sites and the iodine to dissociate the $\mathrm{BiI}$ but rather the BiI interacts with the oxide surface as a molecule. The addition of moisture in the system appears to not influence the behavior of the iodine (Fig. $2 \mathrm{~b} / \mathrm{d}$ ) by an amount exceeding the uncertainty of the measurement, suggesting the speciation remains the same in moist helium.

\section{Oxygen carrier gas}

The results obtained from two experiments performed in dry and another two experiments in moist oxygen are depicted in Fig. 3. In one dry experiment (Exp VI) and one water saturated (Exp VIII), two peaks are observed, one with an adsorption enthalpy of roughly -70 to $-75 \mathrm{~kJ} \mathrm{~mol}^{-1}$ and the other one approximately $-80 \mathrm{~kJ} \mathrm{~mol}^{-1}$. The suggested explanation regarding the speciation of the peak around $-80 \mathrm{~kJ} \mathrm{~mol}^{-1}$ involves the oxidation of the iodine present in the bismuth monoiodide in oxidation state -1 to monatomic iodine while in parallel bismuth oxide is formed.
This speciation is supported by a correlation describing the relationship between the sublimation enthalpy of an element and its adsorption enthalpy on fused silica [15]. The correlation is given as: $-\Delta H_{\text {ads }}=(0.85 \pm 0.06) \Delta H_{\text {subl }}+(3.7 \pm 0.06)$ which, using $\Delta H_{\text {subl }}(\mathrm{I})=107 \mathrm{~kJ} \mathrm{~mol}^{-1}[17]$, results in $-\Delta$ $H_{a d s}(\mathrm{I})=87 \pm 15 \mathrm{~kJ} \mathrm{~mol}^{-1}$.

Thus, we can state that the introduction of oxygen as a carrier gas introduces a systematic increase in the volatility of the deposited iodine compounds formed, when compared to dry and moist helium. Beyond formation of monatomic iodine, the iodine can react again with oxygen to form yet more volatile iodine oxides. This is supported by experiments on monatomic iodine with and without addition of oxygen to an otherwise inert carrier gas. When oxygen is added, an increase in volatility is observed indicating further reactions between monatomic iodine and oxygen [18]. The products of such reactions presumably make up the lower deposition temperature peaks observed in the oxygen carrier gas experiments of the present study. Adsorption enthalpies for these species range between $-76 \mathrm{~kJ} \mathrm{~mol}^{-1}$ down to $-67 \mathrm{~kJ} \mathrm{~mol}^{-1}$. In one experiment (Exp IX), the formed product was volatile enough to not adsorb to the column at all. Thus, it was found in the charcoal trap located downstream of the column. Therefore, only a lower limit for the adsorption enthalpy could be determined as 
$-\Delta H_{a d s}<64 \mathrm{~kJ} \mathrm{~mol}^{-1}$. The variability of the depositions observed in oxygen atmosphere indicate that small variations of one or more experimental parameters may significantly influence the speciation of iodine in oxygen containing carrier gas. A plausible explanation for the observed behaviour would be variations of the oxidation state of the surface leading to the absence or presence of metal centers in specific oxidation states that may catalyse the formation of certain volatile species. Specific information regarding the reaction products is not possible to extract with our current available data and experimental setup. To extend the capabilities of the setup, the thermal gradient would need to be expanded to include temperatures below room temperature. This would increase the range of determinable adsorption enthalpies to lower absolute values. Furthermore, experiments with better-defined starting conditions with respect to surface oxidation of the steel and under systematic variation of the oxygen and moisture content of the carrier gas could help to discriminate between the different oxidised volatile iodine species and to understand the mechanism of their formation.

An interesting observation with respect to the influence of oxygen on the speciation of iodine evaporated from LBE was made in a thermochromatography experiment performed in dry helium atmosphere using an iodine-containing LBE sample prepared using non-reduced LBE. We assume that this sample contained a significantly higher amount of oxygen dissolved in the LBE compared to all other samples used in the present study. The result of this experiment is shown in Fig. 4. We observe two depositions, a large peak with an adsorption enthalpy of $-103 \mathrm{~kJ} \mathrm{~mol}^{-1}$ very similar to the depositions assigned to $\mathrm{BiI}$ in all other helium experiments described above, and a smaller deposition with an adsorption enthalpy of $-83 \mathrm{~kJ} / \mathrm{mol}$ that can be assigned to monoatomic iodine.

This indicates that a small fraction of the iodine present in the LBE most probably in oxidation state -1 has been oxidized to monoatomic iodine by the oxygen dissolved in the LBE. Thus, the volatilization and deposition behavior of iodine in LBE is not only sensitive to carrier gas oxygen but also to oxygen dissolved in the LBE.

\section{Hydrogen carrier gas}

Figure 5 shows the results of four experiments performed in hydrogen carrier gas, two of them in dry gas (Exp X \& XI, Fig. 5a and c) and two additional experiments in water saturated hydrogen (Exp XII \& XIII, Fig. 5b and c).

The Monte Carlo simulations using the experimental results obtained in dry hydrogen yield adsorption enthalpy values of $-106 \mathrm{~kJ} \mathrm{~mol}^{-1}$ and $-87 \mathrm{~kJ} \mathrm{~mol}^{-1}$, respectively, with an uncertainty of $10 \mathrm{~kJ} \mathrm{~mol}^{-1}$. Both values agree within the uncertainty margins with the adsorption enthalpies determined for the depositions observed in dry helium gas
(Table 1 and Fig. 2a and c, mean value of $-98 \mathrm{~kJ} \mathrm{~mol}^{-1}$ ) which were assigned to the deposition of the molecular species BiI in analogy to similar experiments performed using fused silica columns [15]. Thus, we conclude that the species depositing on 316L steel in hydrogen gas is likely the same. However, we note that the variability of the results in the hydrogen experiments of the present study is apparently larger compared to the results obtained in helium, where almost perfect agreement was found between two similar experiments. This variability may not necessarily result from a change in iodine speciation but rather from surface changes induced by the reducing hydrogen gas. The only chemical plausible change in iodine speciation in hydrogen containing systems would be the formation of hydrogen iodide, a compound that is gaseous at room temperature [19]. The formation of such a volatile iodine compound would be a potential safety hazard for nuclear systems. The results presented here indicate that this compound is either not formed when iodine evaporates from LBE in hydrogen containing gases, or it is decomposed while it is transported down the gradient tube. The gas phase formation of hydrogen iodide involves the attack of two iodine atoms simultaneously on each of the hydrogen atoms joined in the $\mathrm{H}_{2}$ molecule, suggesting formation of $\mathrm{HI}$ via this mechanism is impossible with carrier-free iodine [19]. Alternatively, formation of HI could occur via heterogeneously catalysed reactions on the steel surface [20]. The results obtained here indicate that such reactions do not occur under the present conditions. Similar results have been obtained in fused silica columns, both with iodine evaporated from LBE as well as using monatomic iodine produced from fission [15, 21].

In the water saturated experiments we observed adsorption enthalpies of $-105 \mathrm{~kJ} \mathrm{~mol}^{-1}$ and $-134 \mathrm{~kJ} \mathrm{~mol}^{-1}$. The first experiment (Exp XII) aligns well with the observed behavior in one of the dry hydrogen experiments as well as all experiments in helium, suggesting an iodine speciation of BiI. In Exp XIII a deposition temperature of $271{ }^{\circ} \mathrm{C}$ and correspondingly a higher absolute value of the adsorption enthalpy is observed, compared to the behavior seen in Exp XII as well as all the helium carrier gas experiments. In principle, surface changes due to carrier gas effects could cause this exceptionally high deposition temperature. The oxide layer on the steel surface may be reduced upon contact with hydrogen, making a larger number of metallic adsorption sites available. An increase in the measured dew point by a few degrees when initiating heating of the column confirms that indeed such reduction processes occurred in our experiments. To bring the dew point down in hydrogen was commonly more time consuming than in other gases, indicating continuous production of water in the system. Chemisorption of iodine to these metallic sites could bind it more strongly compared to the adsorption on an oxide layer and thus lead to higher deposition temperatures and larger 
absolute values of the adsorption enthalpies. Such effects have been observed in thermochromatography experiments of polonium in $316 \mathrm{~L}$ steel columns, where an increase of the deposition temperature of up to $268{ }^{\circ} \mathrm{C}$ was observed in columns exposed to hydrogen for several hours [11]. However, in experiments in dry hydrogen representing the conditions with the strongest reducing potential (Exp X and XI) we do not see a systematic increase of deposition temperature in comparison to the experiments in helium carrier gas, but rather deviations to slightly higher and lower deposition temperatures in the two individual experiments. This makes it unlikely that a simple reduction of the surface causes the variations observed here. Thus, we suspect that the reason of the moderate differences between the results of Exp X and XI rather results from variations in the morphologies of the surfaces of the individual columns. This would not be surprising, since the columns were not subjected to a defined pretreatment procedure before the experiments. Exposure of the stainless steel surface oxide layer to heated hydrogen is an established method to increase the porosity of the surface [22]. To take into account the formed porosity of the surface, we applied the mobile adsorption model described in [11]. This method has additional capabilities compared to the used Monte Carlo calculation in that it takes into account the available surface area for either packed columns or columns with porous or uneven surfaces. Calculating the needed additional surface area for a species with $-\Delta H_{a d s}=87 \pm 5 \mathrm{~kJ} \mathrm{~mol}^{-1}$ to adsorb at $174{ }^{\circ} \mathrm{C}$ we arrive at an increase of the specific surface area of at least a factor 20.

The moderate increase in bonding strength observed in Exp XIII may be the result of complex corrosion and restructuring processes occurring at the surface in flowing moist hydrogen. For example, breakaway corrosion and accumulation of iron oxides near the surface has been observed in pre-oxidized samples of stainless steel exposed to flowing moist hydrogen [23]. From application of the mobile adsorption model again, we see a larger required increase in column surface area to make the adsorption enthalpies of the two experiments overlap (approximately a factor 50). This is consistent with the increased attack on the steel surface seen in hydrogen when moisture is introduced [23]. The column used in Exp XIII was indeed stored for substantially longer time under ambient air before the experiment was performed, enabling a stronger pre-oxidation compared to Exp XII and thus a more substantial impact of the hydrogen reduction on the surface. We conclude that for a more detailed study of the influence of reactive gases on the adsorption properties of steel surfaces reproducible pretreatment of the surfaces is necessary to achieve defined starting conditions. Summarizing, while not all effects concerning the adsorption behavior of iodine evaporated from LBE in reducing carrier gases have been fully elucidated and explained in the present study, we have shown that no highly volatile species such as HI occur under the studied conditions.

\section{Conclusions}

The volatilization of iodine from LBE has been investigated in various atmospheres. The main volatile species were identified by their different deposition temperatures in a thermal gradient. Their adsorption properties regarding their retention on steel surfaces were quantified at the conditions prevailing in LBE-based nuclear systems. When evaporated from LBE into a dry or water saturated inert carrier gas, iodine forms a single species adsorbing with $-\Delta H_{\text {ads }}$ of about 97 to $106 \mathrm{~kJ} \mathrm{~mol}^{-1}$. The presumed identity of this species is bismuth monoiodide based on thermodynamic evaluations for the same system in [15]. Influence of moisture in inert gas appears to be negligible with no changes to the chemical speciation. However, the presence of small amounts of oxygen in the LBE sample appears to be sufficient to influence the speciation of the iodine by oxidizing a small fraction to monoatomic iodine.

In oxygen atmosphere we observe the formation of multiple species of iodine adsorbing at or below $75{ }^{\circ} \mathrm{C}$ with adsorption enthalpies ranging from $-83 \mathrm{~kJ} \mathrm{~mol}^{-1}$ (Exp VIII) all the way down to where we can only determine a limiting value of $-\Delta H_{a d s}<64 \mathrm{~kJ} \mathrm{~mol}^{-1}$ (Exp IX). The deposited species in oxygen are most likely monatomic iodine and various iodine oxides or hydroxides. For a more detailed and precise characterization of the adsorption behavior of these species an extension of the thermal gradient below room temperature would be required. Speciation information may still be ambiguous with such a gradient, however identification of the actual number of occurring species as well as their relative volatility may be enlightening.

In dry and moist hydrogen atmosphere we find adsorption enthalpies ranging from $-87 \mathrm{~kJ} \mathrm{~mol}^{-1}$ to $-134 \mathrm{~kJ} \mathrm{~mol}^{-1}$. The most likely deposited species is BiI, with surface effects induced by the reactive gas causing larger variations compared to the analogous experiments in helium atmospheres. An important result is that formation of the very volatile molecule $\mathrm{HI}$ is not observed when evaporating iodine from LBE in hydrogen containing atmospheres.

This experimental campaign has successfully measured the strength of the adsorption interaction between the iodine species evaporated from LBE and stainless steel surfaces under conditions relevant for an LBE reactor system during normal operation and accident scenario conditions. The data obtained regarding iodine and general adsorption characteristics of stainless steel is valuable for safety assessments and provides a good foundation for continued work on other volatile radionuclides present in an LBE reactor system. 
Acknowledgements This work was funded by the European Comission within the project MYRTE under EURATOM HORIZON2020 Grant Agreement No. 662186.

Author contributions EK: Conceptualization, Methodology, Software, Validation, Formal analysis, Investigation, Writing-Original Draft, Visualization. JN: Conceptualization, Validation, Data Curation, Writing-Review \& Editing, Visualization, Supervision, Project administration, Funding acquisition. RE: Validation, Methodology, Software, Writing-Review \& Editing, Visualization. IID: Methodology, Resources. A.V. Methodology, Resources AT: Validation, Writing-Review \& Editing, Supervision.

Funding Open Access funding provided by Lib4RI - Library for the Research Institutes within the ETH Domain: Eawag, Empa, PSI \& WSL.

Open Access This article is licensed under a Creative Commons Attribution 4.0 International License, which permits use, sharing, adaptation, distribution and reproduction in any medium or format, as long as you give appropriate credit to the original author(s) and the source, provide a link to the Creative Commons licence, and indicate if changes were made. The images or other third party material in this article are included in the article's Creative Commons licence, unless indicated otherwise in a credit line to the material. If material is not included in the article's Creative Commons licence and your intended use is not permitted by statutory regulation or exceeds the permitted use, you will need to obtain permission directly from the copyright holder. To view a copy of this licence, visit http://creativecommons.org/licenses/by/4.0/.

\section{References}

1. OECD/NEA (2015) Handbook on lead-bismuth eutectic alloy and lead properties. Mater Compatib Thermalhydraul Technol Nucl Sci OECD Publishing, Paris. https://doi.org/10.1787/42dcd531-en

2. Aït Abderrahim H, Baeten P, De Bruyn D, Heyse J, Schuurmans P, Wagemans J (2010) MYRRHA, a multipurpose hybrid research reactor for high-end applications. Nucl Phys News 20(1):24-28. https://doi.org/10.1080/10506890903178913

3. Morewitz HA (1982) Fission product and aerosol behavior following degraded core accidents. Nucl Technol 53(2):120-134

4. Soffer L, Burson SB, Ferrell CM, Lee RY, Ridgely JN (1995) Accident source terms for light-water nuclear power plants: final report, NUREG-1465, U.S. Nuclear Regulatory Commission, Washington, USA

5. Girault N, Dickinson S, Funke F, Auvinen A, Herranz L, Krausmann E (2006) Iodine behaviour under LWR accident conditions: lessons learnt from analyses of the first two Phebus FP tests. Nucl Eng Des 236(12):1293-1308. https://doi.org/10.1016/j.nucengdes. 2005.12.002

6. Gonzalez Prieto B, Lim J, Mariën A, Rosseel K, Martens JA, Van den Bosch J, Neuhausen J, Aerts A (2014) Non-uniform polonium distribution in lead-bismuth eutectic revealed by evaporation experiments. J Radioanal Nucl Chem 302:195-200. https:// doi.org/10.1007/s10967-014-3264-1

7. Okamoto H (2010) I-Pb (Iodine-Lead). J Phase Equilibria Diffus 31(3):320-321. https://doi.org/10.1007/s11669-010-9700-1

8. Predel B (1992) Landolt-Börnstein - Group IV physical chemistry volume 5B: phase equilibria, crystallographic and thermodynamic data of binary alloys B-Ba - C-Zr. Springer, Berlin, Heidelberg. https://doi.org/10.1007/b43647
9. Aerts A, Gonzalez Prieto B, Neuhausen J (2020), Behaviour of spallation, activation and fission products in LBE. In: Konings RJM, Stoller RE (eds) Comprehensive nuclear materials, vol 5, 735-765. https://doi.org/https://doi.org/10.1016/B978-0-12803581-8.11612-1

10. Jolkkonen M, Wallenius J (2013) Report on source term assessment for the ETDR (ALFRED). Report of the EU FP7 Project LEADER

11. Zvara I (2008) The inorganic radiochemistry of heavy elements: methods for studying gaseous compounds. Springer, Berlin

12. Maugeri EA, Neuhausen J, Gonzalez Prieto B, Aerts A, Mendonça TM, Stora T, Eichler R (2018) Adsorption of volatile polonium species on metals in various gas atmospheres: Part III - adsorption of volatile polonium on stainless steel $316 \mathrm{~L}$. Radiochim Acta 106(2):125-134. https://doi.org/10.1515/ract-2017-2807

13. Danilov II, Neuhausen J, Vögele A, Eichler R, Müller E, Türler A (2018) Evaporation of iodine and polonium from liquid leadbismuth eutecticum, Annual Report 2017, Laboratory for Radiochemistry. Paul Scherrer Institut, Villigen

14. Nucleonica GmbH (2019) Nuclide datasheets, nucleonica nuclear science portal (www.nucleonica.com), Version 3.0.151.0001, Karlsruhe, Germany

15. Karlsson E, Neuhausen J, Eichler R, Aerts A, Danilov II, Vögele A, Türler A (2020) Thermochromatographic behavior of iodine in fused silica columns when evaporated from lead-bismuth eutectic. J Radioanal Nucl Chem 326:1249-1258. https://doi.org/10.1007/ s10967-020-07420-1

16. Fredriksson W, Malmgren S, Gustafsson T, Gorgoi M, Edström K (2012) Full depth profile of passive films on 316L stainless steel based on high resolution HAXPES in combination with ARXPS. Appl Surf Sci 258:5790-5797. https://doi.org/10.1016/j.apsusc. 2012.02.099

17. Barin I (1995) Thermochemical data of pure substances, 3rd edn. Wiley, Weinheim

18. Bächmann K, Matschoss V (1975) Separation of nuclear reaction products in the gas phase I: separation of Tc in a flow of oxygen. J Inorg Nucl Chem 35(7/8):15-19. https://doi.org/10.1016/00221902(75)80116-3

19. Wiberg N, Holleman AF (2007) Lehrbuch der Anorganischen Chemie, 102nd edn. De Gruyter, Berlin

20. Stampfl C, Ganduglia-Pirovano MV, Reuter K, Scheffler M (2002) Catalysis and corrosion: the theoretical surface-science context. Surf Sci 500(1-3):368-394. https://doi.org/10.1016/S00396028(01)01551-5

21. Eichler B, Baltensperger U, Kalberer M, Gäggeler HW, Trautmann N, Eberhardt K, Nähler A, Mendel M (1996) Adsorption of carrier-free radioactive isotopes of iodine on solid surfaces. Paul Scherrer Institut anual report 1995 Annex IIIA: Solid state research at large facilities, INIS-MF-14888, Villigen

22. Badin V, Diamanti E, Forêt P, Horgnies M, Darque-Ceretti E (2015) Design of stainless steel porous surfaces by oxide reduction with hydrogen. Mater Des 86:765-770. https://doi.org/10. 1016/j.matdes.2015.07.142

23. Hooshyar $\mathrm{H}$ (2016) High temperature corrosion of stainless steels in low oxygen activity environments the effect of $\mathrm{H}_{2}$ and $\mathrm{H}_{2} \mathrm{O}$, Ph.D. Thesis, Chalmers University of Technology, Gothenburg, Sweden

Publisher's Note Springer Nature remains neutral with regard to jurisdictional claims in published maps and institutional affiliations. 